Informal Logic

\title{
Justifying Particular Reasoning in a Legal Context
} On Neil MacCormick's 'Universalisable Particular Thesis'

\section{Jingjing $\mathrm{Wu}$}

Volume 40, numéro 3, 2020

URI : https://id.erudit.org/iderudit/1071501ar

DOI : https://doi.org/10.22329/il.v40i30.5994

Aller au sommaire du numéro

\section{Éditeur(s)}

Informal Logic

\section{ISSN}

0824-2577 (imprimé)

2293-734X (numérique)

Découvrir la revue

\section{Citer cet article}

Wu, J. (2020). Justifying Particular Reasoning in a Legal Context: On Neil MacCormick's 'Universalisable Particular Thesis'. Informal Logic, 40(3), 423-441. https://doi.org/10.22329/il.v40i30.5994

\section{Résumé de l'article}

Le raisonnement particulier est sans doute le type de raisonnement juridique le plus courant. Neil MacCormick a proposé que, dans un contexte juridique, un raisonnement particulier justifiable doit être universalisable. Cet article vise à: (1) étudier la thèse de MacCormick; (2) expliquer comment un particulier peut jamais être universel en s'inspirant de la formule de Scott Brewer sur le raisonnement par analogie; (3) comprendre davantage la thèse de MacCormick en examinant certains des arguments avancés par ses opposants; (4) utiliser la «procédure de jugement pilote» développée par la Cour européenne des droits de l'homme comme exemple pour illustrer la pertinence de la thèse du particulier universalisable dans les pratiques juridiques d'aujourd'hui. 


\title{
Justifying Particular Reasoning in a Legal Context: On Neil MacCormick's 'Universalizable Particular Thesis'
}

\author{
JINGJING WU
}

\author{
David C. Lam Institute for East-West Studies \\ Hong Kong Baptist University \\ Kowloon, Hong Kong, China \\ j.j.wu@outlook.com
}

\begin{abstract}
Particular reasoning is arguably the most common type of legal reasoning. Neil MacCormick proposed that, in a legal context, justifiable particular reasoning has to be universalizable. This paper aims to: (1) investigate MacCormick's thesis; (2) explain how a particular can ever be universal by drawing inspiration from Scott Brewer's formula on reasoning by analogy; (3) further comprehend MacCormick's thesis by considering some of the arguments advanced by its opponents; (4) use the 'pilot-judgement procedure' developed by the European Court of Human Rights as an example to illustrate the relevance of the universalizable particular thesis in today's legal practices.
\end{abstract}

Résumé: Le raisonnement particulier est sans doute le type de raisonnement juridique le plus courant. Neil MacCormick a proposé que, dans un contexte juridique, un raisonnement particulier justifiable doit être universalisable. Cet article vise à: (1) étudier la thèse de MacCormick; (2) expliquer comment un particulier peut jamais être universel en s'inspirant de la formule de Scott Brewer sur le raisonnement par analogie; (3) comprendre davantage la thèse de MacCormick en examinant certains des arguments avancés par ses opposants; (4) utiliser la «procédure de jugement pilote» développée par la Cour européenne des droits de l'homme comme exemple pour illustrer la pertinence de la thèse du particulier universalisable dans les pratiques juridiques d'aujourd'hui.

Keywords: analogy, legal reasoning, particular reasoning, pilot-judgement procedure, universal particular thesis 


\section{Introduction}

To justify particular reasoning, Neil MacCormick (2006) submitted that:

There is $[\ldots]$ no justification without universalisation; motivation needs no universalization; but explanation requires generalization. For particular facts - or particular motives - to be justifying reasons they have to be subsumable under a relevant principle of action universally stated (p. 21).

This understanding of particular reasoning in relation to universalization is as famous as its controversy. ${ }^{1}$ Therefore, in this small thought-experiment, I would like to put MacCormick's thesis (hereafter referred to the universalizable particular thesis or the thesis) in an informal logic representation, in order to: (1) exam its validity; and (2) elaborate on its practical application in today's legal context. The main question of this article, thus, is in what sense is the universalizable particular thesis valid? Its corollary question is how can a particular ever be universal?

The next part of this paper provides a working definition of particular reasoning in the legal context. Part 3 revisits the universalizable particular thesis proposed by MacCormick. Part 4 investigates the justification of this thesis by drawing inspiration from reasoning by analogy proposed by Scott Brewer. Part 5 advances three implications of the thesis regarding its practical, legal application. Part 6 addresses some of the criticisms this thesis has attracted thus far. Finally, to show the current relevance of this thesis, I introduce the 'pilot-judgement procedure' developed by the European Court of Human Rights (ECtHR). The pilot judgement procedure in the ECtHR is used as an example not only because such procedure is a good instance of applying the universalizable particular thesis, but also because the universalizable particular thesis is especially relevant when human rights issues are on the line. Universal principles of human rights are usually

\footnotetext{
${ }^{1}$ Its controversy led to a gathering of a dozen legal scholars at Edinburgh in 2005 and a lively discussion about the validity, implications, and limitations of this thesis. For this discussion, see Part 7.
} 
challenged by relativistic arguments (such as cultural relativism) ${ }^{2}$, which has caused much confusion regarding the legal justification of human rights. Therefore, a good grip of the universalizable particular thesis - the logic that to an extent clarifies the confusion derived from universality vs. relativity-helps to advance the human rights legal debate as a whole.

\section{Particular reasoning: a working definition}

Particular reasoning is arguably the most common form of legal reasoning. The idea of the particular, almost always coupled with the concept of universal, can be traced back to the beginning of Western philosophy, appearing in Aristotle's discussion on kath' hekasta (of a particular) as opposed to katholou (universal, as 'of a whole'). ${ }^{3}$ In this sense, universals and particulars are opposite categorical propositions (Abrusci et al. 2013, 1017), where the former can serve as a predicate while the latter cannot. 'Particular reasoning,' as used in the legal context, is derived from this understanding.

In the legal context, universals are usually presented as rules or principles. Formally, universals (whether rules or principles) correspond to the universal quantification (i.e., 'for all subjects X, statement $\mathrm{P}(\mathrm{X})$ holds'). ${ }^{4}$ In this sense, universality is intrinsically linked with one of the essential characteristics of the rule of law, namely legal equality (i.e., equals being treated equally). Particular reasoning, in contrast, involves taking specific facts or circumstances into consideration when applying universal rules or principles. One may argue that, in the sense just described, almost all legal reasoning (or at least all legal reasoning worth discussing) involves particular reasoning because one of the main tasks of legal argumentation is to bring the particularity of a case into the

\footnotetext{
${ }^{2}$ For the universality vs. relativity of human rights debate, see, e.g. Donnelly 2007, O'Sullivan 2000.

${ }^{3}$ Given the scope of this article, it cannot cover the rich philosophical discussion of this issue and will instead focus on its implications in the legal context. For helpful insights into Aristotle's thesis on universals vs. particulars, see, for example, Sharples 2009.

${ }^{4}$ This form of logic is usually denoted as $\forall \mathrm{x} P(\mathrm{x})$.
} 
open. Hence, for the present paper, I shall limit the term 'particular reasoning' to the following account: Because of particular facts or circumstances, presupposed universal rules or principles do not apply or must be altered. On this account, particular reasoning can also be seen as a defensive argumentation manoeuvre, which, by appealing to particular circumstances, argues for the exclusion or deviation from certain rules or principles qua the universals. This account is used not only because it is in line with the one MacCormick (2005) adopts when dealing with particular reasoning in the legal context and is thus relevant for the current discussion, but also because this definition aligns with the relativistic arguments that are often used in the human rights legal context.

A good example of particular reasoning regarding human rights may be the well-known 'Asian values' (see, e.g., Kim 2010). As a long-standing view supported by many Asian countries, such an argument calls for an Asian perspective of human rights and hence a deviation from the international human rights doctrines (see, e.g., 1993 Bangkok Declaration on Human Rights ${ }^{5}$ ). In other words, this argument holds that for Asian countries, because of their particularities (notably their cultural, social, and legal backgrounds), they should be permitted to deviate from some universal human rights norms enshrined in the international legal doctrines. For example, one common Asian value holds that individual rights cannot trump collective and common good. To what extent and in what sense such a deviation is justifiable? The universalizable particular thesis may just provide the answer for this question.

\section{Universalizable particular thesis}

The universalizable particular thesis submitted that justifiable particular reasoning ${ }^{6}$ must be universalizable. In other words, in

\footnotetext{
5 For the text of the 1993 Bangkok Declaration on Human Rights, see https://www.hurights.or.jp/archives/other_documents/section1/1993/04/finaldeclaration-of-the-regional-meeting-for-asia-of-the-world-conference-onhuman-rights.html (Last accessed 15 June 2020).

${ }^{6}$ Herein, I distinguish 'justifiable' from 'justified' legal reasoning. For legal reasoning to be justifiable, it has to satisfy relevant justification rules. For legal reasoning to be justified, it has to be decided as such by the relevant judicial procedures.
} 
order to be qualified as justifiable, particular reasoning must be able to apply to all cases that bear the same particulars. As MacCormick (2006) put it: "(there is) no justification without universeralization” (p. 21).

Suppose that, for example, a sign in a park says, 'Do Not Feed the White Swan!' One day, a black swan enters the park unnoticed. Allen is caught feeding it and is issued a fine. Allen argues that, because the sign only mentioned the white swan, feeding the black swan did not fall under the park rule. The park ranger eventually decides Allen did not break the rule and thus does not apply the fine. So far, according to the result (i.e., the ranger decided Allen did not break the rule and did not issue a fine), this is an example of justified particular reasoning. Furthermore, this decision implies that the argument for 'this black swan' also applies to 'all black swans,' while 'Allen' could be replaced by anyone. That is to say, the particular case in which 'Allen feeding this black swan in this park is allowed' already implies that 'anyone feeding any black swan in this park is allowed.' This simplified example shall help to illustrate the underlining logic of the universalizable particular thesis.

MacCormick also points out that rules or principles in the legal context are 'defeasible' universals. This means that there is always room for raising particulars that may require a revision of legal rules or principles or their application. Nonetheless, once such particulars are acknowledged as permitted exceptions to the relevant rules or principles, they become universalized exceptions. To make this point, MacCormick uses the famous conjoined twins case, ${ }^{7}$ stating that no matter how 'unlikely to be repeated' (according to the judgement, this case is 'very unique'), it is still considered a type-case (MacCormick 2005, p. 90). If in the future another case satisfies all the relevant particulars, the same judgement should be passed on. This understanding of universal vis-à-vis particular reasoning - taking universalizability as a criterion for determining the justifiability of particular reasoning - is worth citing in MacCormick's own words:

${ }^{7}$ Re A (children) (conjoined twins) [2000] 4 All ER 961. This case is discussed in MacCormick 2008. 
This is so, even if one wisely allows for the ever-present possibility of unforeseen events and circumstances requiring one to revise hitherto accepted near-certainties. If 'particularism' is understood as no more than a position that insists on this openness to evaluate new cases and circumstances when these arise, then it is acceptable. But this is openness to new particulars within a justifying schema of defeasible universals, and each new exception once acknowledged becomes itself a universalized exception (MacCormick 2005, p. 94, italics added).

If I may put it differently: the borderline between particulars and universals should be drawn from the side of the universals. This brings us to the essence of the universalizable particular thesis: only particulars that are universalizable are justifiable particulars.

Another example should help explain why justifiable particular reasoning should be universalizable in the legal context. Suppose that, in a country $\mathrm{C}$, there is a legal rule stating that 'all minors have the right to free education.' To put it formally: for all minor $\mathrm{x}, \mathrm{x}$ has a right to free education in $\mathrm{C}$. Bianca, who came to $\mathrm{C}$ with her refugee parents, was s a minor but was denied this right. She thus brought a lawsuit against C. Now assume that the State's attorney argued that Bianca, and Bianca alone, was not entitled to free education in $\mathrm{C}$. Without further reasoning, this argument (which is also particular reasoning) can be represented as follows: Although Bianca is a minor, she does not have the right to free education in $\mathrm{C}$. Hence, although the law says that 'all minors have the right to free education in $\mathrm{C}$,' it is interpreted as 'all minors except Bianca have the right to free education in C' or 'Some minors have the right to free education in C.'

At least two aspects of this argument are unjustifiable, which hinges on the characteristics of the rule of law. First, within a legal order, one cannot simply argue that a law is false without invoking the procedure to revise or amend the law. Therefore, if the law in question says 'all minors,' it cannot be altered to in relation to some minors. Second, under the basic principles of the rule of law, equal cases must be treated equally. Any universal rule or principle must be applied equally to equals. As such, one cannot state that an individual subject is singled out from their equals and subject to a particular rule. Hence, thus far, there is no legal 
ground to justify such particular reasoning.

This, again, is a simplified example. However, it serves its purpose to distil the essence of the justification of the universalizable particular thesis: Since any particular reasoning that can be considered justifiable needs to elaborate further on why Bianca does not qualify for free education, as soon as this is put forward-no matter how peculiar the reason may be - it shall be considered as a universally applicable rule. That means anyone who is relevantly similar to Bianca will not qualify for free education in $\mathrm{C}$ as well. Failing to satisfy this requirement, as singling Bianca out as an individual did, cannot hold under the principle of equality and the rule of law.

So far, this thesis may seem self-evident. However, in order to address the opposing opinions, it is necessary to delve into the process of the justification of particular reasoning.

\section{The process of justification: how can particulars be univer- sal?}

If one goes back to the very origin of the terms 'universal' and 'particular' - back to the ancient Greek philosophers and to Aristotle, one may find a fundamental problem hidden in a so far rather satisfying rule of justification. According to its definition, a universal is "a repeatable item, something common to many things; hence $[\ldots]$ is located in the many places in which these things are located', while a particular, its antithesis, is 'a non-repeatable item ... has a unique occurrence or location..."” (Harte 2009, p. 97). These definitions challenge the foundations of the universalizable particular thesis: since particulars are unique and non-repeatable, how can they ever be universalizable? Using the on-going example of Bianca, if we hold Bianca as an individual with all her particular characteristics, how could we come to an argument defending her right (or lack thereof) to free education in $\mathrm{C}$ that is also universalizable?

In this section, inspired by Scott Brewer's analysis of reasoning by analogy, I argue that these definitions of universals and particulars can indeed co-exist with the universalizable particular rule above. It should be noted that this is not just a 'rescue mission'; it 
is, in fact, the underlining logic embedded in the process of justifying any particular reasoning in a legal context.

In his well-known paper, "Exemplary Reasoning: Semantics, Pragmatics, and the Rational Force of Legal Argument by Analogy," Brewer (1996) set out his model of exemplary reasoning. He indicated that "exemplary reasoning is best reconstructed as a patterned sequence of reasoning steps that have three analytically distinct components. These are to be understood as three individually necessary and jointly sufficient conditions" (p. 962). First, there is the process of abduction, in order (usually for the jurists) to find the 'analogy-warranting rule' (AWR). Second, there is the process of confirming (or disconfirming) the AWR by testing, rationalising, and adjusting it. Third, there is the process of applying the AWR "discovered in the first step and confirmed in the second step to the particular example or examples (exemplary propositions) that originally triggered the exemplary reasoning process - the example subjudice, as it were"(p. 963). The logical form of this process is represented as follows:

[To use Brewer's original terms: $\mathrm{x}, \mathrm{y}$ are the sources; $\mathrm{z}$ is the target. F, G are the shared characteristics. $\mathrm{H}$ is the inferred characteristic.]

Where $x, y, z$ are individuals and $F, G, H$, are predicates of individuals:

Step 1: $z$ has characteristics $F, G, \ldots$.

Step 2: $x, y, \ldots$ have characteristics $F, G, \ldots$.

Step 3: $x, y, \ldots$ also have characteristic $H$.

Step 4: The presence in an individual of characteristics $F, G, \ldots$ provides sufficient warrant for inferring that $\mathrm{H}$ is also present in that individual.

Step 5: Therefore, there is sufficient warrant to conclude that $H$ is present in $z$.

(4 i) The presence in an item of $F$ and $G$ makes it (sufficiently) probable that $\mathrm{H}$ is also present (Brewer 1996, pp. 962-968).

A comprehensive review of Brewer's reasoning by analogy model is beyond the scope of this article. The reason for introducing Brewer's model, nevertheless, is that reasoning by particulars 
(particular reasoning) shares a similar process. The following puts particular reasoning into a syllogism (form I):

[OF denotes operative facts. NC denotes normative consequences. $\mathrm{OF}(\mathrm{p})$ denotes particular operative facts.]

(1) Whenever OF, then NC,

(2) $\mathrm{OF}(\mathrm{p})$,

(3) $O F(p)$ provides sufficient warrant for inferring that $\mathrm{OF}(\mathrm{p})$ is significantly different from $\mathrm{OF}$ so that its normative consequence should be allowed to deviate from NC.

(4) Then not NC.

This form has a variation (form II):

$[\mathrm{NC}(\mathrm{p})$ denotes particular normative consequences that is not NC.]

(1) Whenever OF, then $\mathrm{NC}$,

(2) $\mathrm{OF}(\mathrm{p})$,

(3) Whenever $\mathrm{OF}(\mathrm{p})$, then $\mathrm{NC}(\mathrm{p})$,

(4) Therefore, $\mathrm{NC}(\mathrm{p})$.

The universalizable particular rule of justification lies between step (1) and (2) of both forms, which can be presented as:

(1a) OF has characteristics A, B, ...

(1b) $\mathrm{OF}(\mathrm{p})$ has characteristics $\mathrm{E}, \ldots$

(1c) The presence of an item $E, \ldots$ makes $O F(p)$ significantly different from $\mathrm{OF}$, in that all the items have $\mathrm{E}, \ldots$ are not OF.

The above representations show that, although a particular case is defined as 'unique' hence 'non-repeatable,' it does not affect the rule of justification that requires particular reasoning to be universalizable. This lies in the logical link between step (1) and (2) (i.e., (1a) - (1c)). It means particular reasoning does not (and cannot) 
identify every characteristic that makes the subject a particular (and therefore unique). Instead, the justification rules of particular reasoning only articulate the salient feature(s) that make the case sufficiently particular to be excluded or allowed to deviate from universal rules or principles. Hence, the universalizability test hinges on the salient feature having a universalizable characteristic, which warrants any subject sharing the same feature to be excluded or allowed to deviate from the universal rule or principle.

Returning to the example of Bianca, we established that her opponent's argument to merely indicate that Bianca is not entitled to free education in $\mathrm{C}$ is not justifiable. Her opponent may, however, search for a universalizable salient feature to defend such position. For example, the opponent may argue that because Bianca does not hold citizenship in $\mathrm{C}$, she is not entitled to free education in $\mathrm{C}$, which is thus far defendable in this case. I will turn to this point in the next section.

Before doing so, I will just summarize that the crux of the justification process is to identify which universalizable particulars are deemed salient. This means to bring out the salient features from other relevant ones. Such distinction holds the key to test whether an argument invoking particular reasoning is justifiable.

\section{The implication of the justification process}

Thus far, we can identify at least three implications from the justification process of particular reasoning that are relevant to the current discussion.

First, the process shows that not all particulars are sufficient for grounding particular reasoning, but only those which are universalizable. This explains how 'unique and non-repeatable' particulars can indeed entail universals. In fact, particular reasoning does not (and cannot) include all the relevant particulars that make the given subject unique and therefore particular. Rather, it brings out the features that are salient in the given context which are also universalizable. Those salient features explain why the subject is particular enough so that it should be excluded or permitted to deviate from the given rule. The universalizability warrants such deviation still obeys the rule of law. 
Second, let us turn back to the example of Bianca one more time. Following form I above, the opponent may simply argue that Bianca is not considered a qualified candidate for free education in C. Following form II, the opponent may argue that, although she is indeed a minor, because she is not a citizen of $\mathrm{C}$, Bianca does not have the right to free education in $\mathrm{C}$. (Implied proposition: only those minors who are citizens of $\mathrm{C}$ have a right to free education in C).

Although both arguments are logically defendable, they entail significantly different burdens of argument, and therefore require a different extent of dialogical constructiveness. According to Walton and Krabbe (1995), there are six main general types of dialogue depending on what is being pursued, namely persuasion, negotiation, inquiry, deliberation, information, and eristic. ${ }^{8}$ Each dialogue type constitutes a separate normative model of argumentation and therefore serves a particular normative goal. A constructive argument, in this sense, contributes to a goal of the type of dialogue in which that argument was put forward. A legal argument by particular reasoning has a similar function as an inquiry, whose goal is to prove (or disprove) hypotheses (or opponent's statements). Therefore, a legal argument that is also dialogically constructive has to serve the goal of proving hypotheses and hence moving the dialogue forward.

Accordingly, in the example of Bianca, if the opponent is following form I, such reasoning would be considered justifiable until Bianca's lawyer makes a justifiable counter-argument: in this case, contesting why Bianca should be indeed considered a qualified minor under the relevant law. Thus, this is an inertial move with no dialogical function other than stalling the arguing process. If, however, the opponent uses form II, she would take up the burden of argument in claiming that, for instance, because Bianca is not a citizen, she is not entitled to free education in $\mathrm{C}$. This argument voluntarily pushes the dialogue forward by explicating the salient features. Therefore, although both forms are logically correct, only form II is considered dialogically constructive.

\footnotetext{
${ }^{8}$ Note that there are also 'mixed' types that combine the prototypes.
} 
It is remarked that such dialogical constructiveness is particularly relevant for international public law and its tribunals, especially international human rights law and its treaty bodies. Since the enforceability of international legal instruments is relatively limited compared to domestic ones. Dialogical constructiveness is, therefore, an important function of legal argumentation to facilitate the adjudication and implementation of the given law.

Third, to decide whether particular reasoning is justified is for the jurists to decide whether the implicit or explicit rule of universalizability (i.e., 1 [c]) is valid. In the Bianca case, it is. Because Bianca is not a citizen, she is not entitled to free education in $\mathrm{C}$. The universalizability rule here is only the minors that are citizens of country $\mathrm{C}$ have the right to free education. The adjudicator, therefore, has to decide whether this universalizability rule is a justified one according to the given law.

\section{Response to opposing arguments}

The universalizable particular thesis is far from non-controversial. Among its critiques, some are particularly worth addressing, for not only do they relate to a legal context (others focus on, for instance, moral implications of the thesis) but they also provide the opportunity to clarify the original thesis, its justification, and its implications.

One of the most common criticisms against the universalizable particular thesis is that particulars (or individual cases) should have their importance addressed in the law. In this sense, to emphasise the universal side of the story is a biased theory (Bell 2006, Christodoulidis 2006). As Bell (2006) argued:

our legal process of adjudication is designed to hold in tension the universal and the particular: in part because we recognize that our rules and procedures are imperfect but also because $[. .$.$] we value$ individuals in their singularity and need to respect this (p. 41).

Indeed, it may seem tempting to argue for the value of individuals, especially in a legal order that is based on liberal ideology. ${ }^{9}$ However, such view does not hold in this particular debate. Drawing

${ }^{9}$ I use 'ideology' as a value-neutral term. 
the line from the universal side does not mean we leave particulars qua individuals unattended. Rather, it means that the reasoning to justify such particulars and individuals should be able to hold for all cases that share the same salient features. As discussed above, under the principles of the rule of law such as equality, all the cases that share the same salient features should be treated equally. The universalizable particular thesis, therefore, has little to do with whether to take individuals seriously, but has to do with the validity of the reasoning. That is, for legal reasoning to be justifiable, it has to be valid against universal rules. In other words, a universalizable particular is a requirement of the quality (validity) of reasoning and is not about attributing value to the particular or the universal.

The second criticism argues that because "the parties choose the issues that they wish to raise and the arguments relevant to them" (Bell 2006, p. 45), there is a good chance that both parties may want to ignore some particulars. This means that although the particular case before the court is solved, "it does not necessarily adopt a very universalistic perspective" (Bell 2006, p. 45). Like the first critique, this argument also misrepresents the thesis. It is precisely because the parties do not want to (and cannot) raise every single issue that what is raised is deemed salient. The fact that not every feature can be discussed in court should not be used against the universalizability of the case, but rather proves that a particular case can be universalizable in terms of its reasoning: it is universal regarding its salient particulars.

The third criticism takes a different route. Rather than focusing on the relationship between the universal and the particular, it emphasizes the possible confusion of universalization and generalization. Christodoulidis (2006) argues that the more we increase the specificity of a case, the more a new set of standards for evaluation are required. Therefore, each case requires a process of generalization in order to 'make sense of the case,' to categorize it, and to classify it. Hence, what is at issue in the process of judging is generalization, not universalization. In other words, "generalization rather than universalization is the category we look to in order to justify judgement...” (p. 98). To prove this point, Christodoulidis gives the following example, which is worth citing in detail: 
The night the Government announced its response to the House of Lords decision - its response more or less to universalize detention without trial to all suspected terrorists - the Home Secretary Charles Clarke was being interviewed by Jeremy Paxman on the return form Guantanamo Bay of four UK citizens recently released. Paxman asked whether the UK was intending to step up the pressure to secure the release of others from the US Gulag, notably UK residents. 'Oh, no', came the impatient response, 'a whole other set of considerations apply there', Clarke's qualification as to whose human rights we do protect was an objection to the pitching of the generic category: UK citizens but not UK residents, and in any case not others who are neither citizens nor residents (p. 100).

The distinction between UK citizens and UK residents as the reasoning behind the Home Secretary's decision, argued by Christodoulidis, illustrates that MacCormick "misplaces the emphasis on universalization as doing the justificatory work that generalization is in fact doing" (p. 101). He then further cites Günther (1993) and points out that the problem which lies in this misplacement is that: “... with the choice of a specific moral norm (a universal rule) nothing has yet been decided about whether it is justifiable" ( $p$. 101). To put this critique in the context of the ongoing analysis, it means that the universalizable particular thesis does not tell us which feature should be distilled as salient in a particular situation and why it is justifiable to do so.

To address this critique, therefore, the response has to be twofold. One aspect is to address the relationship between the universalization and generalization. The other is to respond to the justifiability of the salient features. I will start with the first. To use the example above: it is highly unlikely that the Home Secretary collected all the names that he did not intend to request for release and happened to find that they shared a common denominator: they were all UK residents but not citizens, and therefore came up with such justification. On the contrary, such distinction, from the onset, is a deduction. UK citizens are a different category from UK residents. Once this differentiation was made salient by the Home Secretary, it became the justification for the differentiated treatments. To put it differently, a valid justification for the Home Secretary's decision cannot be that 'the UK government does not 
intend to request a release for almost all UK residents from the Guantanamo Bay' but it has to be 'all UK residents.' The former is generalization, whereas the latter is universalization. In fact, this is the crux of the universalizable particular thesis: only universal (not general) justifies particular. Moreover, what Christodoulidis may confuse here is the justification of the law (the universal) at issue and the application of it. It is one thing to question whether the distinction between UK residents and UK citizens when it comes to protecting fundamental rights is a valid rule. It is another thing to question the justifiability of the Home Sectary's decision made according to a valid rule. The universalizable particular thesis concerns the latter, while Christodoulidis' critique concerns the former.

This leads us to Christodoulidis' second objection. That is, the universalizable particular thesis does not provide guidance when it comes to deciding which feature should be made salient from a particular case, or in his words, it does not "[justify] the rightness of the substantive standards" (p. 101). This function, indeed, escapes the universalizable particular thesis, which generally serves two goals: to clarify and explicate the justification process of a particular reasoning, and to test the justifiability of particular reasoning. What it cannot do is to come up with this reasoning in the first place. However, because it is mostly a posteriori (Christodoulidis, p. 98) does not mean that it is dismissible. More importantly, because a justifiable (or justified) particular reasoning has to be universalizable, once such particular reasoning is deemed justifiable (or justified), it becomes a priori to all the other cases that share the same salient features. This, as we shall see in the next section, is the case for the ECtHR pilot judgement procedure.

\section{The application of the universalizable particular thesis: ECtHR pilot-judgement procedure}

The development of the pilot judgement procedure of ECtHR is a fitting example for illustrating the relevance of the universalizable particular thesis to current legal practices because the underlining logic of this procedure is, in fact, an adoption of the universalizable particular thesis. 
The first such pilot-judgement is Broniowski v. Poland ([GC], no. 31443/96, ECHR 2005-IX). Broniowski was forced to abandon his property after a change to Poland's borders after the Second World War. The importance of this case is not the award for Broniowski but the obligation for Poland to "provide a remedy 'at the national level"' (Helfer 2018). The ECtHR found that the dispute "originated in a widespread problem which results from a malfunctioning of Polish legislation and administrative practice" affecting 80,000 property claimants and 167 pending applications (Helfer 2018). Afterwards, new legislation was introduced in Poland and pending cases were settled.

After Broniowski, the ECtHR developed this kind of pilotjudgement into a procedure to deal with large groups of cases deriving from the same underlying problem (ECtHR 2009). The procedure operates as follows:

when the Court receives a significant number of applications deriving from the same root cause, it may decide to select one or more of them for priority treatment. In dealing with the selected case or cases, it will seek to achieve a solution that extends beyond the particular case or cases so as to cover all similar cases raising the same issue. The resulting judgment will be a pilot judgment (para. 2. Italics added).

Moreover, it is stated that such a judgement will have the aim, among others, to:

bring about the creation of a domestic remedy capable of dealing with similar cases (including those already pending before the Court awaiting the pilot judgment), or at least to bring about the settlement of all such cases pending before the Court (para. 3).

This procedure not only has the practical function of relieving the Court of excessive workload but is also based on the universalizable particular thesis for the following reasons.

First, it starts with the Court identifying a number of pending cases that share 'the same root cause.' Each case is of course unique in its own way, but the same root cause is considered as a salient feature in deciding these cases.

Second, the solution given by the Court is supposed to "extend(s) beyond the particular case or cases so as to cover all simi- 
lar cases raising the same issue" (para. 2). This usually involves a reform at the national, legislative, or administrative level. This is to say that the judgment applies universally to all cases bearing the same salient feature(s).

Third, the Court also noted that "not every pilot judgement will lead to an adjournment of cases, especially where the systemic problem touches on the most fundamental rights of the person under the Convention" (para. 7). This means there might be cases that, despite sharing salient features with the pilot-case, are deemed particular in their own terms. Those cases, therefore, fall outside the purview of the pilot-judgement. Moreover, as the Court mentioned, one criterion of such an exception was not affecting 'the most fundamental rights' under the Convention. Such a particularization, thus, becomes another universalization.

In short, from selecting the pilot case (the particular) and determining the 'shared root cause' (the 'salient feature(s)') to issuing a judgement applying to all the similar cases (universalizability) and deciding the exception of such a judgement (another universalized particular), the whole pilot-judgement procedure of the ECtHR illustrates the practical relevance of the universalizable particular thesis in the current legal system.

\section{Conclusion}

A particular is, by definition, unique and non-repeatable. However, this does not affect the rule by which particular reasoning is justifiable when and only when it is universalizable. This is because particular reasoning needs not (and should not) identify every feature that makes it particular; rather, it only articulates the salient feature (or features) that explains the reason for being excluded or deviating from the universal rules or principles. Universalizability, in this sense, lies in the salient feature as distilled from the particular. In other words, any subject that shares such feature should also be excluded or allowed to deviate from the given rule or principle. To decide whether such reasoning is justified is to decide whether the rule indicating universalizability of the salient feature is valid under the given law. In addition, constructive particular reasoning must also take up the burden of 
argument and move the dialogue forward (by following the form II mentioned above).

This understanding of particular reasoning is important for our current legal context as shown by the pilot-judgement procedure of the ECtHR. It is also particularly relevant for human rights issues, as those issues are usually subject to the universal vs. relativistic debate. Countries often use relativistic arguments to justify human rights violations. For instance, developing countries may resort to their economic status as an excuse for not living up to their obligations regarding economic, social, and cultural rights; or some religious states would ask for an opt-out from provisions regarding gender-quality. For those cases, it is then important to ask: Are such arguments universally justifiable? Is the universalization of these particulars valid under the given legal order? This conclusion, therefore, sheds light on the justification of relativistic arguments under international human rights law in general. In a way, this conclusion contrasts Donnelly (2007)'s relative universality thesis, which argues that the more specific a right, the more relative justificatory standard applies. According to Donnelly, "(H)uman rights are (relatively) universal at the level of the concept" (p. 299), whereas at the level of a particular conception, "relativity is not merely defensible but desirable" (p. 299). In light of the universalizable particular thesis, I submit that at least in a legal context, a justifiable relativistic argument concerning a human right should always be universalizable, regardless of how specific that right is.

\section{References}

Abrusci,V. M., Casadio, C, Medaglia, M. T and Camillo P. 2013. Universal vs. particular reasoning: a study with neuroimaging techniques. Logic Journal of IGPL 21 (6): 1017.

Bell, John. 2006. The institutional constraints on particularism. In The Universal and the particular in legal reasoning, eds. Zenon Bankowski and James MacLean. Ashgate.

Brewer, Scott. 1996. Exemplary reasoning: semantics, pragmatics, and the rational force of legal argument by analogy. Harvard Law Review 109 (5). 
Bankowski, Zenon and James MacLean (eds), 2006, The universal and the particular in legal reasoning. Ashgate.

Christodoulidis, Emilios. 2006. Eliding the particular: A comment on Nail MacCormick's "particulars and universals." In The universal and the particular in legal reasoning, eds. Zenon Bankowski and James MacLean. Ashgate.

Donnelly, Jack. 2007. The relative universality of human rights. Human Rights Quarterly 29.

European Court of Human Rights. 2009 The Pilot-Judgment Procedure information note issued by the Registrar:

https://www.echr.coe.int/Documents/Pilot_judgment_procedure ENG.pdf

Günther, Klaus. 1993. The sense of appropriateness. Translated by John Farrell, State University of New York Press.

Helfer, Laurence R. 2018. Redesigning the European Court of Human Rights: Embeddedness as a deep structural principle of the European human rights regime. EJIL 19.

Harte, Verity. 2009. What's a particular, and what makes it so? Some thoughts, mainly about Aristotle, in Particulars in Greek philosophy: The seventh $S$. V. Keeling Colloquium in ancient philosophy, ed. Robert W. Sharples. Brill.

Kim, So Yong. 2010. Do Asian values exist? Empirical tests of the four dimensions of Asian values. Journal of East Asian Studies (10): 315 .

MacCormick, Neil. 2005. Rhetoric and the rule of law. Oxford: Oxford University Press.

MacCormick, Neil. 2006. Particulars and unviersals. In The Universal and the particular in legal reasoning, eds. Zenon Bankowski and James MacLean. Ashgate.

MacCormick, Neil. 2008. Practical reason in law and morality. Oxford: Oxford University Press, 173-181.

O'Sullivan, D. 2000. Is the declaration of human rights universal? The International Journal of Human Rights 4(1): 25-53.

Sharples, Robert W. 2009. Particulars in Greek philosophy: The seventh $S$. V. Keeling Colloquium in ancient philosophy. Brill.

Walton, Douglas, and Erik C. W. Krabbe. 1995. Commitment in dialogue: Basic concepts of interpersonal reasoning. State University of New York Press. 